\title{
Gene expression alteration during redox-dependent enhancement of arsenic cytotoxicity by emodin in HeLa cells
}

\author{
Xiao Jing WANG, Jie YANG, Hui CANG, Yan Qiong ZOU, Jing YI* \\ Department of Cell Biology, Shanghai Second Medical University, 280 Chongqing Road, Shanghai 200025, China
}

\begin{abstract}
Emodin (1,3,8-trihydroxy-6-methylanthraquinone) could enhance the sensitivity of tumor cells to arsenic trioxide $\left(\mathrm{As}_{2} \mathrm{O}_{3}\right)$-induced apoptosis via generation of ROS, but the molecular mechanism has not been elucidated. Here, we carried out cDNA microarray-based global transcription profiling of $\mathrm{HeLa}$ cells in response to $\mathrm{As}_{2} \mathrm{O}_{3} /$ emodin cotreatment, comparing with $\mathrm{As}_{2} \mathrm{O}_{3}$-only treatment. The results showed that the expression of a number of genes was substantially altered at two time points. These genes are involved in different aspects of cell function. In addition to redox regulation and apoptosis, ROS affect genes encoding proteins associated with cell signaling, organelle functions, cell cycle, cytoskeleton, etc. These data suggest that based on the cytotoxicity of $\mathrm{As}_{2} \mathrm{O}_{3}$, emodin mobilize every genomic resource through which the $\mathrm{As}_{2} \mathrm{O}_{3}$-induced apoptosis is facilitated.
\end{abstract}

Keywords: microarray, reactive oxygen species, apoptosis, arsenic trioxide, emodin.

\section{INTRODUCTION}

The therapeutic effect of arsenic trioxide $\left(\mathrm{As}_{2} \mathrm{O}_{3}\right)$ has been affirmed for acute promyelcytic leukemia, but some other leukemia and a variety of human tumors, especially the solid tumors, are less sensitive or insensitive to $\mathrm{As}_{2} \mathrm{O}_{3}$ treatment [1]. It is noticed that a number of chemotherapeutic drugs, including $\mathrm{As}_{2} \mathrm{O}_{3}$, kill tumor cells with dependence on cellular reactive oxygen species (ROS), and that manipulation of cellular redox state may enhance the cytotoxicity of these drugs [2-4]. We previously reported that the sensitivity of different tumor cells to $\mathrm{As}_{2} \mathrm{O}_{3}$-induced apoptosis is positively related to their inherent cellular ROS level and the elevation of intracellular ROS level by ROS generation agent could enhance the effects of $\mathrm{As}_{2} \mathrm{O}_{3}[5,6]$.

In an attempt to search for a natural and low-toxic ROS generator, we recently found that emodin $(1,3,8$ trihydroxy-6-methylanthraquinone), a natural anthraquinone derivative, rich in Chinese herbal medicine rhubarb, could generate ROS intracellularly. When cotreating tumor cells with $\mathrm{As}_{2} \mathrm{O}_{3}$, emodin could sensitize cells to $\mathrm{As}_{2} \mathrm{O}_{3}$-induced apoptosis in $\mathrm{HeLa}$ and other cell lines derived from the solid tumors. Two transcription

\footnotetext{
*Correspondence: Jing YI

Tel: +86-21-63846590(ext 776565); Fax: +86-21-53065329;

E-mail: yijing@shsmu.edu.cn
}

factors known to be sensitive to cellular redox, nuclear factor $\mathrm{\kappa B}(\mathrm{NF}-\mathrm{\kappa B})$ and activator protein (AP-1) were inhibited by emodin-elicited ROS elevation, whereas a series of major apoptotic signaling events, i.e. MTP collapse, cytochrome $\mathrm{C}$ release and caspases activation were promoted $[7,8]$. But the precise molecular mechanism through which ROS facilitates $\mathrm{As}_{2} \mathrm{O}_{3}$-induced tumor cell apoptosis has not been elucidated. In order to study the gene expression profile affected by emodin-mediated ROS generation and emodin-enhanced apoptosis, we performed cDNA microarray in $\mathrm{HeLa}$ cells exposed to $\mathrm{As}_{2} \mathrm{O}_{3}$ /emodin cotreatment or $\mathrm{As}_{2} \mathrm{O}_{3}$-only treatment at two time points using BioStar H40s 4096-clone cDNA microarrays.

In this study, we demonstrated the differences in the profiles of mRNAs expression in $\mathrm{As}_{2} \mathrm{O}_{3}$-only treated and $\mathrm{As}_{2} \mathrm{O}_{3} /$ emodin cotreated HeLa cells. The global effect of emodin was seen: 793 and 480 genes, respectively at the early and late time points, differed in expression level by a factor of $\geq 2$. Through such a profound affection on gene expression, emodin completes its enhancement of arsenic cytotoxicity.

\section{MATERIALS AND METHODS}

\section{Cell culture and treatment}

HeLa cells were obtained from American Type Culture Collection (Manassas, VA). Cells were maintained in DMEM (GibcoBRL, Gaithersburg, MD) with antibiotics and $10 \%$ fetal bovine serum, in a humidified atmosphere with $5 \% \mathrm{CO}_{2}$ at $37^{\circ} \mathrm{C}$. $\mathrm{As}_{2} \mathrm{O}_{3}$, emodin (6- 
methyl-1, 3, 8-trihydroxyanthraquinone) and N-acetyl-cystein (NAC) were purchased from Sigma (St, louis, MO). Cells were seeded in 24-well plates at $1 \times 10^{5} \mathrm{cells} / \mathrm{ml}$ and might be incubated with $\mathrm{As}_{2} \mathrm{O}_{3}$ $(2 \mu \mathrm{M})$ or together with emodin $(10$ and $30 \mu \mathrm{M})$ or plus NAC $(1.5$ $\mathrm{mM}$ ), with daily change of drug-containing medium.

\section{Analysis of cell viability and apoptosis}

After exposed to the agents for $48 \mathrm{~h}$, cell viability was assayed using CellTiter 96 Aqueous Non-Radioactive Cell Proliferation Assay (MTS) Kit (Promega, Madison, WI), following the manufacturer's instructions. Absorbance at $490 \mathrm{~nm}$ was directly proportional to the number of living cells in culture.

Apoptotic rates were analyzed by flow cytometry using Annexin V-fluorescein isothiocyarate (FITC)/propidium iodide (PI) kit (BD PharMingen, San Diego, CA) in which Annexin V bound to the apoptotic cells with exposed phosphatidylserine. Samples were prepared according to the manufacturer's instruction and analyzed by flow cytometry on a FACS Calibur (Becton Dickson, San Diego, CA).

\section{Dectection of ROS generation}

2,7-dichlorodihydrofluorescein diacetate (DCFH-DA, Sigma) was used as ROS probe. Cells were first exposed to the agents for $30 \mathrm{~min}$, with pre-incubation of NAC for $4 \mathrm{~h}$ if it was used. DCFH-DA at 10 $\mu \mathrm{M}$ was then incubated with cells for 15 min before a brief PBS rinse and an immediate flow cytometric assay.

\section{Microarray sample preparation, detection and analysis}

cDNA microarray was performed on the pair of the samples. $\mathrm{As}_{2} \mathrm{O}_{3}$-only sample referred to the cells treated with $2 \mu \mathrm{M} \mathrm{As}_{2} \mathrm{O}_{3}$, whereas $\mathrm{As}_{2} \mathrm{O}_{3} /$ emodin cotreatment sample referred to the cells treated with $2 \mu \mathrm{M}$ of $\mathrm{As}_{2} \mathrm{O}_{3}$ in combination with $30 \mu \mathrm{M}$ emodin. Assay was based on two time points. We harvested cells after $6 \mathrm{~h}$ of treatment, in an assumption that emodin-induced upstream signaling and early changes of cell function occurred at this time point. The $24 \mathrm{~h}$ treatment was chosen as later time point because it allowed to see the later gene transcription change induced by emodin, while no substantial apoptosis was yet happened and cell integrity was remained then.

Total RNA was extracted using the Trizol ${ }^{\circledR}$ reagent (Invitrogen, Carlsbad, CA). The subsequent procedures for sample preparation and microarray were performed by Biostar Genechip Inc. (Shanghai, China) according to its protocol subject to BioStar H-40s genechip. Briefly, cDNA was reverse transcripted. The fluorescent cDNA probes were prepared through reverse transcription. The probes for $\mathrm{As}_{2} \mathrm{O}_{3}$-only samples were labeled with Cy3-dCTP, and those for $\mathrm{As}_{2} \mathrm{O}_{3}$ /emodin cotreatment samples were labeled with Cy5-dCTP. Fluorescence intensity was measured for each gene spot. After background subtraction and the whole-chip data normalization, the ratios of gene expression differences between two sets of samples were obtained. BioStar H-40s microarray consisted of 4096 novel or known genes including control system and effective genes (provided by Biostar Genechip Inc, http://www.ugbiostar.com). The control system consists of 96 housekeeping genes as loading control; 16 plant genes, and spotting solution (without DNA, 16 spots) as negative control spots in the array. Chip 1 contained the samples at early time point (6h), and chip 2 at late (24h).

BioStar H-40s genechip covers a series of genes involved in cell components and functions. The differentially expressed genes were further analyzed and classified by Gene Ontology (GO). We identified several categories in which we are particularly interested.

\section{Real time quantitative PCR}

Four mRNA molecules were checked by real time quantitative PCR (ABI Prism 7000 Sequence, PE, USA) to validate the reliability of microarray. Real time PCR was also used to evaluate the reversal effect of NAC, in which ten molecules were quantitated in cells exposed to $\mathrm{As}_{2} \mathrm{O}_{3}$ /emodin cotreatment or to $\mathrm{As}_{2} \mathrm{O}_{3}$ /emodin plus 1 . $5 \mathrm{mM}$ NAC for time similar to that for microarray. RNA was extracted as described above, and cDNA was synthesized using RevertAid $^{\mathrm{TM}} \mathrm{M}-\mathrm{MuLV}$ Reverse Transcriptase (FERMETAS AB, Vilnius, Lithuania). Real-time PCR was performed under conditions described in the SYBR Green I PCR kit (ABI, Branchburg, NJ) $\left(50^{\circ} \mathrm{C}\right.$ for $2 \mathrm{~min} ; 95^{\circ} \mathrm{C}$ for $10 \mathrm{~min} ; 95^{\circ} \mathrm{C}$ for $15 \mathrm{~s} ; 60^{\circ} \mathrm{C}$ for $1 \mathrm{~min} ; 40$ cycles). $\beta$-actin was used as internal control. The experiments were duplicated. The primers for genes were as follows. AKT1: forward: 5'-CGC AGT GCC AGC TGA TGA AG-3' and reverse: 5'-ACA GTC TGG ATG GCG GTT GT-3'; TXNRD1: forward: 5'-GAC GTC ACT GTT ATG GTT AG-3' and reverse: 5'-CTG AGC TAC TAC TCT GAG TC-3'; FLJ14515: forward: 5'-GTC AAC CTG ACT GTG CGA TT-3' and reverse: 5'-CTG GAT CAG AGA AGG CAG CA-3'; NFKBIA: forward: 5'-CTG ATG TCA ACA GAG TTA CCT ACC AG-3' and reverse: 5'-CGT GAA CTC TGA CTC TGT GTC ATA G-3'; HSPF1: forward: 5'-ATT CCA GCT GAT ATC GTC TT-3' and reverse: 5'ATC GTC CTG CCG TCC AGA GT-3'; PRKCD: forward: 5'-CGT TCC TGC GCA TCG CCT TC-3' and reverse: 5'-CGT CGA CTT CCA CTC AGG AT-3'; VDAC1: forward: 5'-ACA AGC TCA GGC TCA GCC AA-3' and reverse: 5'-CAG TCC ACG TGC AAG CTG AT-3'; $\alpha$-actin: forward: 5'-TAT CGA GCA CGG CAT CAT CA-3' and reverse: 5'-GTC ATC TTC TCG CGG TTG GC-3'; ROCK2: forward: 5'-AGG TAT CTG TAC ATG GTA AT-3' and reverse: 5'AGC ATG TTG TCA GGC TTC AC-3'; PIK3C3: forward: 5'-ATG TAG AAG CAG ATG GAT CA-3' and reverse:5'-CAA TCT ATC CAG CCA ATC TAC-3'.

\section{RESULTS}

\section{Emodin altered the cellular redox state and sensitized HeLa cells to arsenic cytotoxicity}

In our previous studies the dose of emodin used in combination with $\mathrm{As}_{2} \mathrm{O}_{3}$ was $10 \mu \mathrm{M}[7,8]$. In order to visualize the gene expression profile clearly in the present study a higher dose was tested. The results of ROS measurement showed that addition of emodin at 10, 30, and 50 $\mu \mathrm{M}$ to HeLa cells for 15 min cause an immediate and dosedependent ROS generation (data not shown). MTS assay showed that emodin at $10 \mu \mathrm{M}$ had no effect on cell viability, and at $30 \mu \mathrm{M}$ caused a mild suppression, but at $50 \mu \mathrm{M}$ led to an obvious decrease in cell viability (data not shown). Therefore emodin at $30 \mu \mathrm{M}$ was selected for its co-treatment with $\mathrm{As}_{2} \mathrm{O}_{3}$.

Exposure of HeLa cells to the $\mathrm{As}_{2} \mathrm{O}_{3}$ /emodin cotreatment elicited an immediate and dramatic increase of ROS in HeLa cells, whereas $\mathrm{As}_{2} \mathrm{O}_{3}$-caused ROS elevation was mild but continuous (Fig. 1).

$\mathrm{As}_{2} \mathrm{O}_{3}$ /emodin cotreatment caused obvious reduction in 


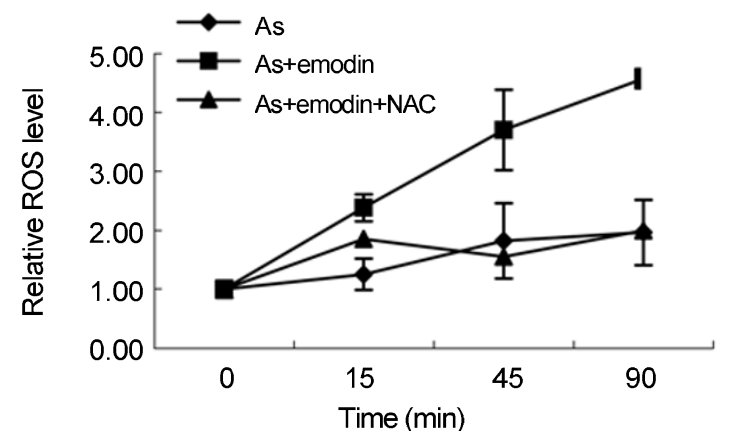

Fig. 1 ROS level (flow cytometry). HeLa cells were treated with $\mathrm{As}_{2} \mathrm{O}_{3} 2 \mu \mathrm{M}$ alone or together with emodin $30 \mu \mathrm{M}$ or plus the antioxidant $\mathrm{N}$-acetyl-L-cysteine (NAC) $1.5 \mathrm{mM}$ for the indicated time (NAC was pre-incubated with cells for $4 \mathrm{~h}$ ). Relative ROS level was represented by the folds of DCF intensity compared to the untreated cells. $\mathrm{As}_{2} \mathrm{O}_{3}$ elicited a mild but continuous elevation of cellular ROS level, whereas two-drug combination dramatically and rapidly augmented ROS level. NAC partially prevented this increase (mean $\pm \mathrm{SD}, \mathrm{n}=3$ ).

the number of viable cells, compared to the untreated and $\mathrm{As}_{2} \mathrm{O}_{3}$-only groups (Fig. 2). Cell number reduction was attributed mainly to the increased apoptosis. Emodin at 30 $\mu \mathrm{M}$ rendered a strong synergistic cytotoxicity to $\mathrm{As}_{2} \mathrm{O}_{3}$, while emodin alone caused no significant cell killing effect, indicating that it enhance $\mathrm{As}_{2} \mathrm{O}_{3}$-induced apoptosis (Fig. $3)$.

\section{Expression of varied genes was altered during emodin-facilitated apoptosis}

Cells exposed to $\mathrm{As}_{2} \mathrm{O}_{3} 2 \mu \mathrm{M}$ in combination with emodin $30 \mu \mathrm{M}$ were set as $\mathrm{As}_{2} \mathrm{O}_{3}$ / emodin-cotreated sample for microarray, as this dose of emodin itself had minimal

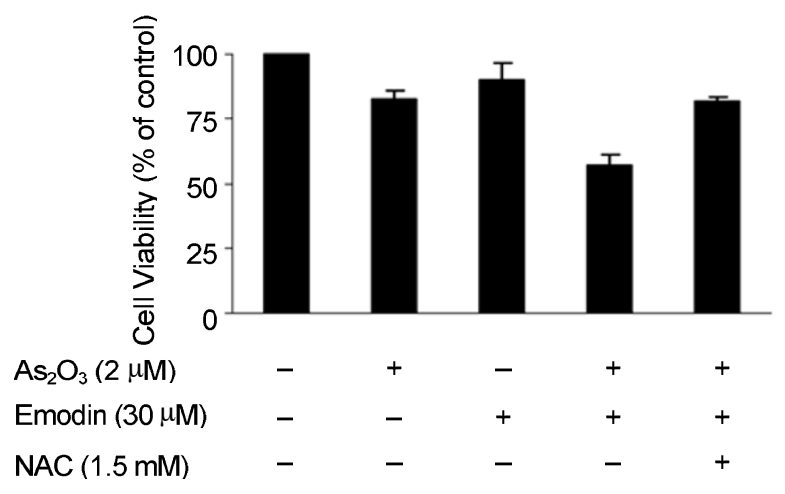

Fig. 2 Cell viability assays (MTS). HeLa cells were treated with $\mathrm{As}_{2} \mathrm{O}_{3}(2 \mu \mathrm{M})$, emodin $(30 \mu \mathrm{M}), \mathrm{As}_{2} \mathrm{O}_{3}$ /emodin $(30 \mu \mathrm{M})$ or together with NAC (1.5 mM) for $48 \mathrm{~h} . \mathrm{As}_{2} \mathrm{O}_{3}$ caused an inhibition in cell viability and emodin enhanced $\mathrm{As}_{2} \mathrm{O}_{3}$-induced viability decrease, while emodin alone had minimal effect on cell viability. NAC partially prevented this decrease (mean $\pm \mathrm{SD}, \mathrm{n}=3$ ).

effect on cell viability, but it could result in an obvious synergistic cytotoxicity. The scanning results of hybridizing signals on gene chips displayed the gene expression alteration between $\mathrm{As}_{2} \mathrm{O}_{3}$-only and $\mathrm{As}_{2} \mathrm{O}_{3}$ /emodin samples at both early (chip1) and late (chip2) time points (Fig. 4). We noticed that the normalized ratio of nearly $80 \%$ and $90 \%$ of the loading control spots were around 1 respectively in two chips and both negative control spots showed low intensity after hybridization (fluorescence intensity $<200$ ), which proved the reliability of the experiment.

The genes with a difference of ratio $\geq 2$ folds were regarded as differentially expressed ones between $\mathrm{As}_{2} \mathrm{O}_{3}-$ only and $\mathrm{As}_{2} \mathrm{O}_{3}$ /emodin samples. There were respectively 793(chip1) and 480(chip2) differentially expressed genes
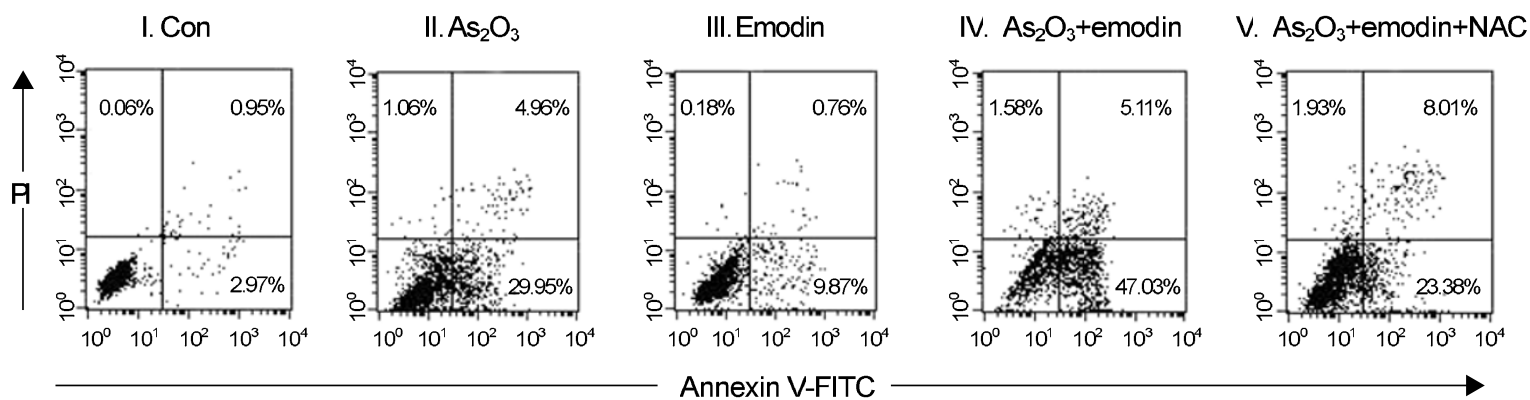

Fig. 3 Apoptotic rates analysis (Annexin V/propidium iodide flow cytometry). HeLa cells were treated with $\mathrm{As}_{2} \mathrm{O}_{3}(2 \mu \mathrm{M})$, emodin $(30 \mu \mathrm{M}), \mathrm{As}_{2} \mathrm{O}_{3}$ /emodin $(30 \mu \mathrm{M})$ or together with NAC $(1.5 \mathrm{mM})$ for $72 \mathrm{~h}$. Cotreatment of HeLa cells with $\mathrm{As}_{2} \mathrm{O}_{3}$ and emodin caused increased apoptosis rate compared to the $\mathrm{As}_{2} \mathrm{O}_{3}$-only and emodin-only group. Enhancing effect of emodin could be reversed by NAC $($ mean $\pm \mathrm{SD}, \mathrm{n}=3)$. 


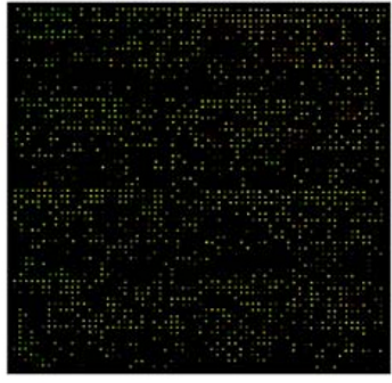

Chip1 (6h treatment)

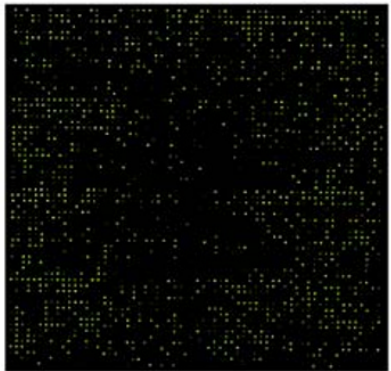

Chip2 (48h treatment )
Fig. 4 The scanning results of hybridizing signals on gene chips displaying the gene expression alteration between $\mathrm{As}_{2} \mathrm{O}_{3}$-only and $\mathrm{As}_{2} \mathrm{O}_{3}$ /emodin samples.

in two chips. Analysis of the filtered differently expressed genes using Gene Ontology (GO) showed that ROS induced expression changes of a variety of genes involved in many aspects of cell function. On the basis of the GO consistent descriptions for gene products, we summarized the up- and down-regulated genes into six categories, i.e. apoptosis, redox, cell signaling, organelle functions, cell cycle and cytoskeleton (Tab. 1). A part of these genes with their Genebank-ID, ratio of mRNA levels, gene defi-
Tab. 1 The number of up and down-regulated genes in 6 categories (fold $\geq 2$ )

\begin{tabular}{llccc}
\hline & \multicolumn{2}{c}{ Up-regulation $^{\mathrm{b}}$} & \multicolumn{2}{c}{ Down-regulation } \\
Category $^{\mathrm{b}}$ & chip1 & chip2 & chip1 & chip2 \\
\hline Apoptosis & 12 & 7 & 12 & 4 \\
Redox- related & 10 & 6 & 8 & 7 \\
Signaling & 43 & 19 & 51 & 32 \\
Organelle & 60 & 27 & 38 & 24 \\
Cell cycle & 13 & 8 & 13 & 17 \\
Cytoskeleton & 11 & 4 & 20 & 13
\end{tabular}

${ }^{a}$ Category represents the six groups of gene functions we defined according to Gene Ontology (GO) terms.

${ }^{\mathrm{b}} \mathrm{Up}$-regulation and Down-regulation indicate genes exhibiting $\geq 2$ fold and $\leq 2$ fold differences in mRNA levels between $\mathrm{As}_{2} \mathrm{O}_{3}$ /emodin cotreatment group and $\mathrm{As}_{2} \mathrm{O}_{3}$-only group.

nition and GO terms were listed (Tab. 2). A part of listed genes was summarized for visualizing the extent to which they changed and for discussion (Fig. 5). The results of real-time PCR of ak027421, NFKBIA, VDACl and $\alpha$-actin genes were consistent with those of cDNA microarray. While the expression level of these four genes were 5, 7.9, 3.3, 20 folds changed on genechips, they were respec-

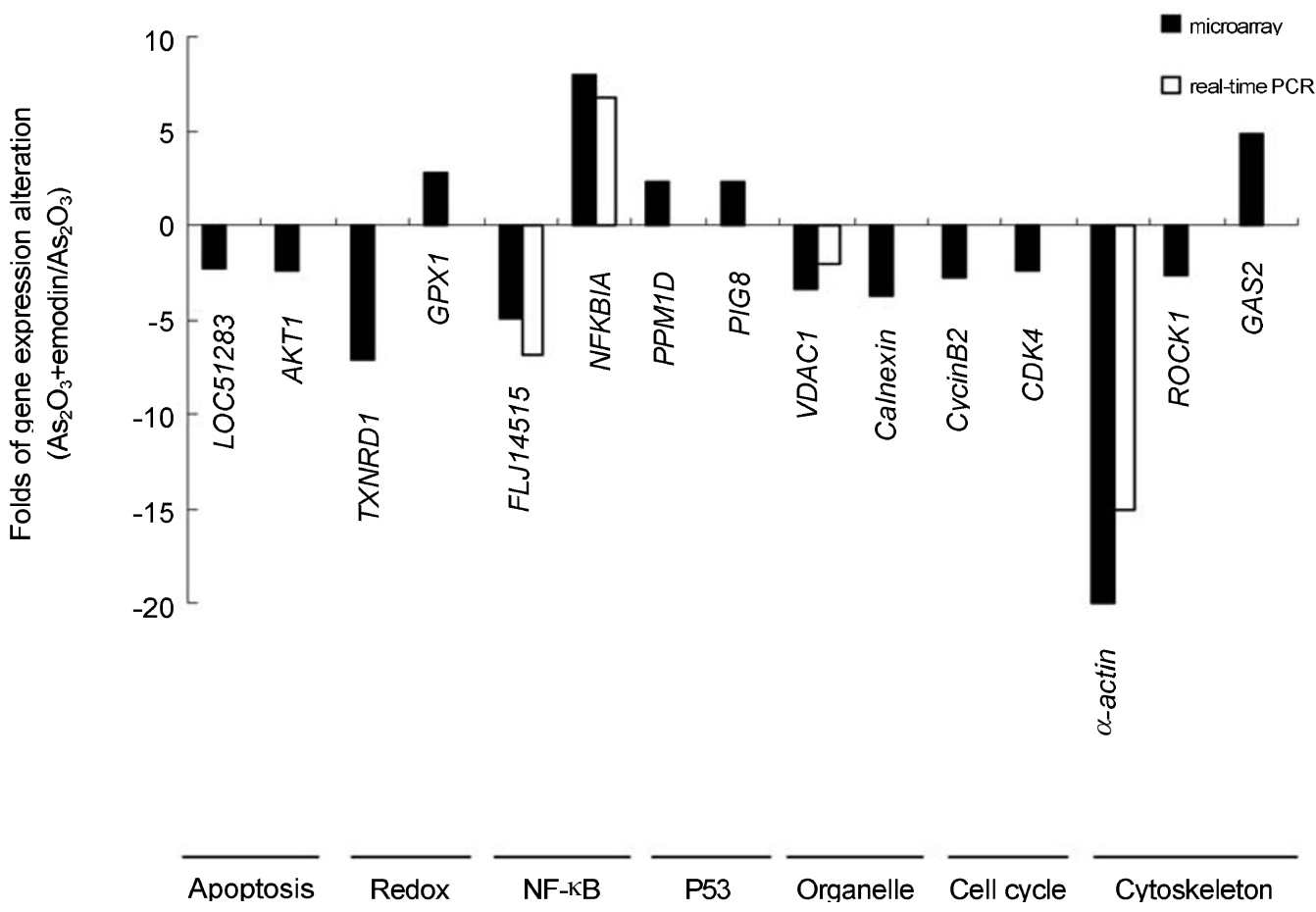

Fig. 5 A part of the listed genes showing the extent to which they changed. These genes belong to different categories and play important roles in redox-enhanced arsenic cytotoxicity. 


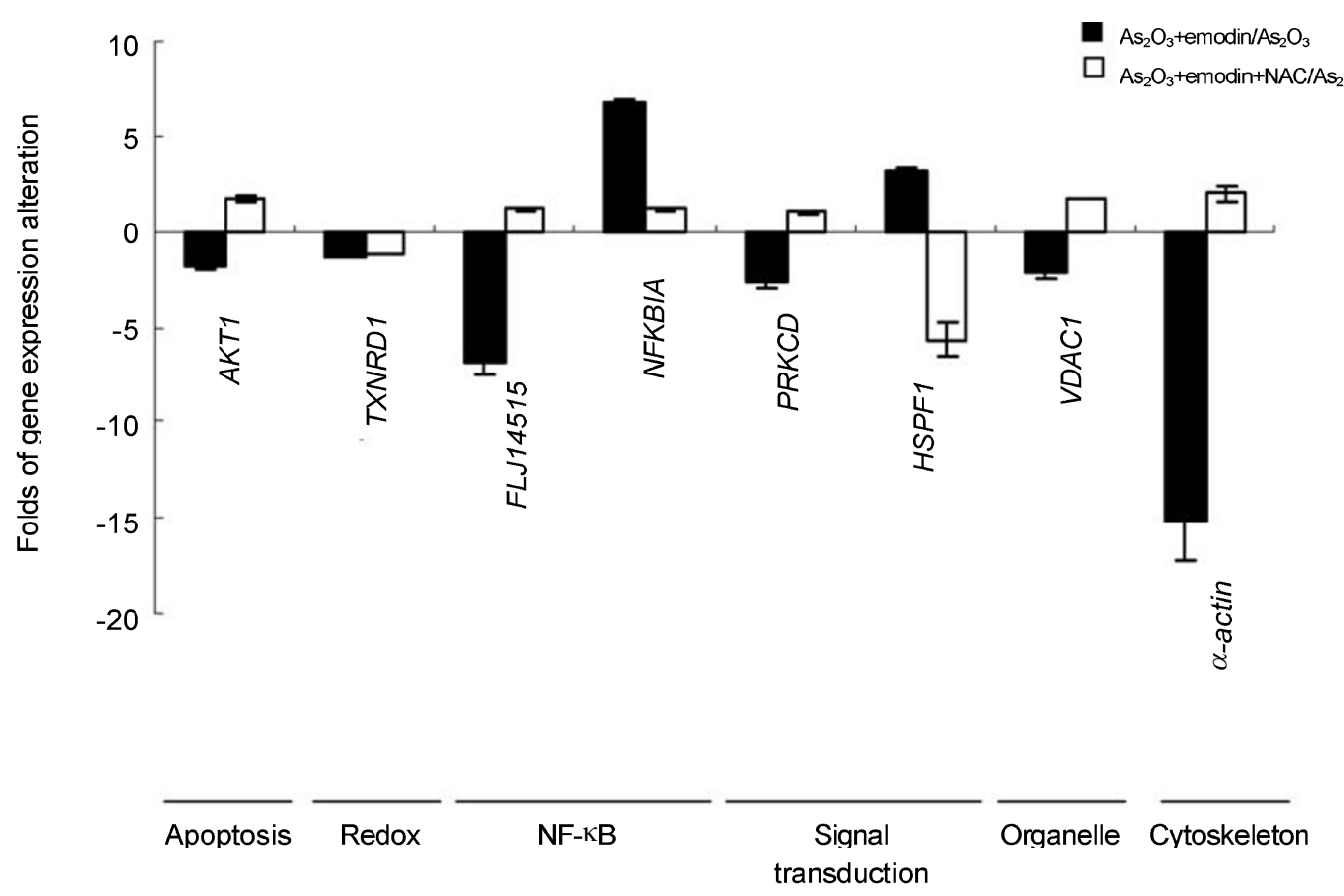

Fig. 6 The comparison of eight genes alterations between samples with $\mathrm{As}_{2} \mathrm{O}_{3}$ /emodin cotreatment and with cotreatment plus NAC (real-time PCR). The copy numbers for each molecule were obtained via normalizing the absolute quantitative values to $\beta$-actin control. Fold change stands for a ratio in which the values for the cotreatment without or with NAC were divided by those for the $\mathrm{As}_{2} \mathrm{O}_{3}$-only treatment (mean $\pm \mathrm{SD}, \mathrm{n}=2$ ).

tively proved to be $6.9,6.8,2.08,15.1$ folds changed in the same direction in real time quantitative PCR (Fig. 5).

The results indicated that, in addition to the genes related to apoptosis and redox regulation, emodin profoundly affected gene expression profile, which ultimately led to an enhanced apoptosis.

\section{Effects of emodin on gene expression alteration could be reversed by anti-oxidant agent $\mathrm{NAC}$}

Based on the gene profiles altered by $\mathrm{As}_{2} \mathrm{O}_{3}$ / emodincotreatment, we selected 10 molecules that involved in the varied aspects and had a substantial alteration on either chip. Real-time quantitative PCR was performed to investigate if their altered expression was resulted from a ROS elevation caused by the combination of $\mathrm{As}_{2} \mathrm{O}_{3}$ and emodin. Cells were exposed respectively to $\mathrm{As}_{2} \mathrm{O}_{3}$ alone, $\mathrm{As}_{2} \mathrm{O}_{3}$ / emodin-cotreatment or $\mathrm{As}_{2} \mathrm{O}_{3}$ / emodin-cotreatment plus NAC. The quantitative values that represented the copy numbers of each mRNAs were calculated into a fold ratio, in which co-treatments without or with NAC were versus $\mathrm{As}_{2} \mathrm{O}_{3}-$ only treatment. Results showed that in 8 of 10 molecules NAC partially or completely reversed the effect of co-treatment, indicating that the differential expression was dependent on ROS (Fig. 6).

\section{DISCUSSION}

The anticancer effect of $\mathrm{As}_{2} \mathrm{O}_{3}$ as a therapeutic agent has been studied for several years. Arsenic treatment has been shown to influence the cell signaling of mitogen-activated protein kinases (MAPKs), activator protein-1(AP1), nuclear factor kappa $\mathrm{B}(\mathrm{NF}-\mathrm{\kappa B}), \mathrm{p} 53$, etc [9]. $\mathrm{As}_{2} \mathrm{O}_{3}-$ induced apoptosis were accompanied by activation of death signals: caspase 3,8 and $9[10,11]$. The generation of ROS appears to consistently accompany arsenic exposure and many evidences suggest that ROS may be a determinant of cellular susceptibility to arsenic [6, 12-15]. Manipulation of ROS may thus be a way to expend the anticancer therapeutic spectrum of $\mathrm{As}_{2} \mathrm{O}_{3}$. Therefore it is interesting to find a clinically safe drug that has synergistic effect with $\mathrm{As}_{2} \mathrm{O}_{3}$ via elevating the ROS level, while keep $\mathrm{As}_{2} \mathrm{O}_{3}$ at a clinically acceptable dose.

As a major component of the widely used Chinese herbal medicine rhubarb, emodin has been used in the remedies for many human diseases including inflammation and cancers. We recently showed that emodin could remarkably enhance the therapeutic effect of $\mathrm{As}_{2} \mathrm{O}_{3}$ in the in vivo models at the doses safe to the animals. Emodin exerts its effects via a ROS-mediated dual signaling regulations i.e. the enhancement of pro-apoptosis and the simultaneous 
Tab. 2 Part of the differently expressed genes(fold change $\geq 2$ )

with their genebank accession number, fold change, gene definition and GO annotation

\begin{tabular}{|c|c|c|c|}
\hline \multicolumn{4}{|c|}{ In chip1 } \\
\hline Genbank_ID & Ratio $^{\mathrm{a}}$ & Gene Definition & GO terms ${ }^{b}$ \\
\hline \multicolumn{4}{|l|}{ Apoptosis } \\
\hline NM_004873 & 0.46 & Homo sapiens BCL2-associated athanogene 5 (BAG5), mRNA & apoptosis \\
\hline NM_016561 & 0.44 & Homo sapiens apoptosis regulator (LOC51283), mRNA & anti-apoptosis \\
\hline NM_002015 & 2.14 & Homo sapiens forkhead box O1A (rhabdomyosarcoma) (FOXO1A), mRNA & anti-apoptosis \\
\hline \multicolumn{4}{|c|}{ 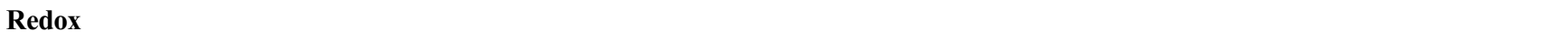 } \\
\hline NM_017853 & 0.32 & Homo sapiens hypothetical protein FLJ20511 (FLJ20511), mRNA & thioredoxin \\
\hline NM_005388 & 0.45 & Homo sapiens phosducin-like (PDCL), mRNA & thioredoxin \\
\hline \multicolumn{4}{|c|}{ Signal transduction } \\
\hline AK027421 & $0.20^{\mathrm{c}}$ & $\begin{array}{l}\text { Homo sapiens cDNA FLJ14515 fis, clone NT2RM1000800, } \\
\text { weakly similar to Mus musculus partial mRNA for B-IND1 protein }\end{array}$ & $\begin{array}{l}\text { NIK-I-kappaB/NF- } \\
\text { kappaB cascade }\end{array}$ \\
\hline NM_020529 & $7.97^{\mathrm{c}}$ & $\begin{array}{l}\text { Homo sapiens nuclear factor of kappa light polypeptide gene } \\
\text { enhancer in B-cells inhibitor, alpha }(N F K B I A) \text {, mRNA }\end{array}$ & $\begin{array}{l}\text { transcription factorl, } \\
\text { cytoplasmic sequestering }\end{array}$ \\
\hline NM_003620 & 2.23 & $\begin{array}{l}\text { Homo sapiens protein phosphatase 1D magnesium-dependent, } \\
\text { delta isoform }(P P M 1 D), \text { mRNA }\end{array}$ & $\begin{array}{l}\text { DNA damage responsel, } \\
\text { activation of } \mathrm{p} 53\end{array}$ \\
\hline NM_000051 & 2.27 & $\begin{array}{l}\text { Homo sapiens ataxia telangiectasia mutated (includes complementation } \\
\text { groups } \mathrm{A}, \mathrm{C} \text { and } \mathrm{D})(A T M), \text { mRNA }\end{array}$ & $\begin{array}{l}\text { DNA damage responsel, } \\
\text { activation of } \mathrm{p} 53\end{array}$ \\
\hline NM_004879 & 2.25 & Homo sapiens etoposide-induced mRNA $(P I G 8)$, mRNA & induction of apoptosis by p53 \\
\hline NM_000581 & 2.79 & Homo sapiens glutathione peroxidase $1(G P X 1)$, mRNA & glutathione peroxidase \\
\hline NM_006254 & 0.31 & Homo sapiens protein kinase $\mathrm{C}$, delta $(P R K C D)$, mRNA & intracellular signaling cascade \\
\hline NM_006145 & 2.20 & Homo sapiens heat shock 40kD protein 1 (HSPF1), mRNA & heat shock protein \\
\hline NM_017569 & 2.51 & Homo sapiens transcription factor (p38 interacting protein) $(P 38 I P)$, mRNA & $\begin{array}{l}\text { transcription factorl, } \\
\text { cytoplasmic sequestering }\end{array}$ \\
\hline \multicolumn{4}{|c|}{ Organelle functions } \\
\hline NM_003374 & $0.30^{\mathrm{c}}$ & Homo sapiens voltage-dependent anion channel 1 (VDAC1), mRNA & $\begin{array}{l}\text { mitochondrial outer } \\
\text { membrane }\end{array}$ \\
\hline NM_002902 & 2.07 & Homo sapiens reticulocalbin 2, EF-hand calcium binding domain ( $R C N 2)$, mRNA & calcium binding \\
\hline NM_001746 & 0.27 & Homo sapiens calnexin $(C A N X)$, mRNA & calcium storage \\
\hline NM_001414 & 0.41 & $\begin{array}{l}\text { Homo sapiens eukaryotic translation initiation factor } 2 \mathrm{~B} \text {, subunit } 1 \text { (alpha, 26kD) } \\
(E I F 2 B 1) \text {, mRNA }\end{array}$ & protein synthesis initiation \\
\hline NM_003034 & 2.29 & $\begin{array}{l}\text { Homo sapiens sialyltransferase } 8 \text { (alpha-N-acetylneuraminate: } \\
\text { alpha-2,8-sialytransferase, GD3 synthase) A (SIAT8A), mRNA }\end{array}$ & $\begin{array}{l}\text { protein amino acid } \\
\text { glycosylation }\end{array}$ \\
\hline NM_004905 & 2.69 & $\begin{array}{l}\text { Homo sapiens anti-oxidant protein } 2 \text { (non-selenium glutathione peroxidase, } \\
\text { acidic calcium-independent phospholipase A2) (KIAA0106), mRNA }\end{array}$ & $\begin{array}{l}\text { serine-type endopeptidase } \\
\text { activity }\end{array}$ \\
\hline NM_001909 & 0.43 & Homo sapiens cathepsin D (lysosomal aspartyl protease) (CTSD), mRNA & lysosome \\
\hline \multicolumn{4}{|l|}{ Cell cycle } \\
\hline NM_004701 & 0.44 & Homo sapiens cyclin B2 (CCNB2), mRNA & mitosis \\
\hline NM_001951 & 2.17 & Homo sapiens E2F transcription factor 5, p130-binding (E2F5), mRNA & cell cycle control \\
\hline NM_000791 & 0.18 & Homo sapiens dihydrofolate reductase $(D H F R)$, mRNA & nucleotide biosynthesis \\
\hline \multicolumn{4}{|c|}{ Cytoskeleton } \\
\hline NM_001100 & $0.05^{\mathrm{c}}$ & Homo sapiens actin, alpha 1 , skeletal muscle $(A C T A 1)$, mRNA & motor \\
\hline AF317696 & 0.43 & Homo sapiens macrophin 1 isoform 4 (MACF1) mRNA, complete cds & actin cross-linking \\
\hline NM_006086 & 0.24 & Homo sapiens tubulin, beta, 4 (TUBB4), mRNA & cytoskeleton \\
\hline NM_003192 & 0.49 & Homo sapiens tubulin-specific chaperone $\mathrm{c}(T B C C)$, mRNA & beta-tubulin folding \\
\hline NM_005256 & 4.85 & Homo sapiens growth arrest-specific 2 (GAS2), mRNA & actin filament \\
\hline NM_001407 & 0.13 & $\begin{array}{l}\text { Homo sapiens cadherin, EGF LAG seven-pass G-type receptor 3, } \\
\text { flamingo (Drosophila) homolog (CELSR3), mRNA }\end{array}$ & cell adhesion \\
\hline NM_002276 & 0.09 & Homo sapiens keratin 19 (KRT19), mRNA & intermediate filament \\
\hline NM_016835 & 0.39 & $\begin{array}{l}\text { Homo sapiens microtubule-associated protein tau }(M A P T) \text {, transcript } \\
\text { variant } 1, \text { mRNA }\end{array}$ & $\begin{array}{l}\text { microtubule associated } \\
\text { protein }\end{array}$ \\
\hline NM_001664 & 0.41 & Homo sapiens ras homolog gene family, member A $(A R H A)$, mRNA & $\begin{array}{l}\text { RHO protein signal } \\
\text { transduction }\end{array}$ \\
\hline NM_004850 & 0.25 & $\begin{array}{l}\text { Homo sapiens Rho-associated, coiled-coil containing protein kinase } 2 \\
(\text { ROCK } 2), \mathrm{mRNA}\end{array}$ & $\begin{array}{l}\text { intracellular signaling } \\
\text { cascade }\end{array}$ \\
\hline
\end{tabular}




\begin{tabular}{|c|c|c|c|}
\hline \multicolumn{4}{|c|}{ In chip2 } \\
\hline Genbank_ID & Ratio & Gene Definition & GO terms \\
\hline \multicolumn{4}{|l|}{ Apoptosis } \\
\hline NM_005163 & 0.41 & Homo sapiens v-akt murine thymoma viral oncogene homolog 1 ( $A K T 1)$, mRNA & anti-apoptosis \\
\hline NM_002880 & 0.42 & Homo sapiens v-raf-1 murine leukemia viral oncogene homolog 1 ( $R A F 1)$, mRNA & apoptosis \\
\hline \multicolumn{4}{|l|}{ Redox } \\
\hline NM_003330 & 0.14 & Homo sapiens thioredoxin reductase $1(T X N R D 1)$, mRNA & oxidoreductase \\
\hline NM_000849 & 0.45 & Homo sapiens glutathione S-transferase M3 (brain) (GSTM3), mRNA & glutathione transferase \\
\hline \multicolumn{4}{|c|}{ Signal transduction } \\
\hline $\begin{array}{l}\text { NM_005500 } \\
\text { enzyme }\end{array}$ & 0.43 & Homo sapiens SUMO-1 activating enzyme subunit 1 (SAE1), mRNA & ubiquitin-like conjugating \\
\hline NM_006819 & 0.37 & $\begin{array}{l}\text { Homo sapiens stress-induced-phosphoprotein } 1 \text { (Hsp70/Hsp90-organizing } \\
\text { protein) }(S T I P 1), \text { mRNA }\end{array}$ & heat shock protein \\
\hline NM_005163 & 0.41 & Homo sapiens v-akt murine thymoma viral oncogene homolog 1 (AKT1), mRNA & signal transduction \\
\hline NM_002647 & 2.24 & Homo sapiens phosphoinositide-3-kinase, class 3 (PIK3C3), mRNA & $\begin{array}{l}\text { phosphatidylinositol } 3 \\
\text {-kinase }\end{array}$ \\
\hline AF181985 & 0.46 & Homo sapiens serine/threonine kinase $(K D S)$ mRNA, complete cds & JNK cascade \\
\hline NM_002222 & 0.49 & Homo sapiens inositol 1,4,5-triphosphate receptor, type 1 (ITPR1), mRNA & $\begin{array}{l}\text { inositol } 1,4,5 \text {-triphosphate } \\
\text { receptor activity }\end{array}$ \\
\hline NM_021138 & 2.41 & Homo sapiens TNF receptor-associated factor $2(T R A F 2)$, mRNA & $\begin{array}{l}\text { transcription factorl, } \\
\text { cytoplasmic sequestering }\end{array}$ \\
\hline \multicolumn{4}{|l|}{ Cell cycle } \\
\hline NM_000075 & 0.41 & Homo sapiens cyclin-dependent kinase $4(C D K 4)$, transcript variant 1 , mRNA & cell cycle control \\
\hline NM_003718 & 0.32 & $\begin{array}{l}\text { Homo sapiens cell division cycle 2-like } 5 \text { (cholinesterase-related cell division } \\
\text { controller) }(C D C 2 L 5) \text {, transcript variant } 1 \text {, mRNA }\end{array}$ & control of mitosis \\
\hline NM_000321 & 0.43 & Homo sapiens retinoblastoma 1 (including osteosarcoma) $(R B 1)$, mRNA & cell cycle checkpoint \\
\hline \multicolumn{4}{|c|}{ Cytoskeleton } \\
\hline NM_005406 & 0.38 & $\begin{array}{l}\text { Homo sapiens Rho-associated, coiled-coil containing protein kinase } 1 \text { (ROCK1), } \\
\text { mRNA }\end{array}$ & $\begin{array}{l}\text { intracellular signaling } \\
\text { cascade }\end{array}$ \\
\hline
\end{tabular}

${ }^{a}$ Ratio of mRNA levels determined by mocroarray.

${ }^{b} \mathrm{GO}$ terms represent the annotation of gene production provided by Gene Ontology(GO).

'Indicates a gene of which the direction of expression change has been verified by real time RT-PCR.

inhibition of anti-apoptosis [8]. In the present study, we aimed to explore through what gene expression profile emodin enhanced $\mathrm{As}_{2} \mathrm{O}_{3}$ cytotoxicity.

Since the microarray focuses the difference existed between a pair of samples, we defined one set of samples as $\mathrm{As}_{2} \mathrm{O}_{3}$-only and another as $\mathrm{As}_{2} \mathrm{O}_{3}$ /emodin cotreatment in order to see the arsenic-based effect of emodin. $\mathrm{As}_{2} \mathrm{O}_{3}$ / emodin combination augments apoptotic rate compared with $\mathrm{As}_{2} \mathrm{O}_{3}$-only treatment. This effect could be partially reversed by antioxidant NAC, which proved that emodin enhances the effect of $\mathrm{As}_{2} \mathrm{O}_{3}$ via the generation of ROS. It is true that emodin at $30 \mu \mathrm{M}$ itself can cause intracellular ROS generation, while it has only minimal impact on cell viability and apoptosis. This may be explained by that the synergistic effect of emodin is dependant on ROS and based on arsenic's efficacy. A simple ROS elevation by emodin at this extent and duration would not elicit dramatic signaling events and the resultant cell death. But rather, $\mathrm{As}_{2} \mathrm{O}_{3}$ has complex cytotoxic effects which emdoin may not possess. Therefore, it was based on the cytotox- icity of $\mathrm{As}_{2} \mathrm{O}_{3}$ that emodin at low dose plays its synergistic anticancer role. HeLa cells exposed to the $\mathrm{As}_{2} \mathrm{O}_{3}$ /emodin cotreatment have more rapid and violent ROS generation. The sudden ROS elevation (dozen of minutes to a few hours after treatments) may function as a signaling trigger to cause wide gene transcriptional alteration, and finally lead to an enhanced apoptosis. This also explains why the time points we selected to do microarray assays (6 and 24 $\mathrm{h}$ after treatments) are later than ROS elevation and earlier than apoptosis occurs ( 2 to $3 \mathrm{~d}$ after treatments).

\section{Emodin enhances $\mathrm{As}_{2} \mathrm{O}_{3}$-induced apoptosis through redox state regulation}

Although HeLa cells do not exhibit apoptotic morphologic changes at $6 \mathrm{~h}$ and $24 \mathrm{~h}$ time points, emodin-mediated regulation of genes related to apoptosis and antiapoptosis is evident in both chips. For example, the expression of $B A G 5$ and LOC51283 genes diminished in chip1. LOC51283 gene is known to be antiapoptotic. $B A G 5$ belongs to $B A G 1$ family, and BAG1 usually functions as an antiapoptotic 
protein through interaction with Bcl-2, RAF kinase, growth factor receptors and HSP70 [16]. Antiapoptosis-related genes $A K T 1$ and $R A F 1$ are down-regulated in chip2. AKT1 gene encodes a serine-threonine protein kinase. Once activated, AKT1 phosphorylates and inactivates components of the apoptotic machinery [17]. RAF1 is involved in MAP kinase-dependent cell cycle control pathways. Remarkably, this down-regulation of antiapoptotic proteins can be abolished by NAC, one of the classic antioxidant agents, implying the alteration is dependent on a ROS elevation caused by emodin.

Emodin augments intracellular ROS level, and ROS fluctuation influences cellular redox state, which may result from or result in the expression of redox-related genes. At the $6 \mathrm{~h}$ time point, two thioredoxin (Trx) related genes, FLJ20511 and PDCC, are down-regulated, while glutathione transferase zeta 1 (GSTZ1) and glutathione peroxidase $1(G p x 1)$ genes are more expressed. At the $24 \mathrm{~h}$ time point, thioredoxin reductase $1(T X N R D 1)$ gene and glutathione S-transferase M3 (GSTM3) gene are substantially less expressed, meanwhile the increased expression is seen for Gpxl and supreoxide dismutase1(SOD1). Trx reductase participates in the reduction of oxidized Trx. Thus, the decrease of reduced formed-Trx and the increase of oxidized formed-glutathion in the cells likely function coordinately as an early transcription response to the emodin treatment. This attenuation of anti-oxidant system will certainly lead to further cellular redox unbalance, though ROS scavenger enzyme SOD, on the other hand, is produced more to rescue the cell from the redox catastrophe.

\section{Emodin influences arsenic effects on multiple signal- ing molecules}

ROS has been implicated as a pivotal regulator in nuclear factor $\kappa \mathrm{B}(\mathrm{NF}-\kappa \mathrm{B})$ activation [18]. Under normal conditions, the inhibitory protein I $\kappa \mathrm{B}$ binds to NF- $\kappa \mathrm{B}$, preventing its access to DNA. Upon phosphorylation of IKB

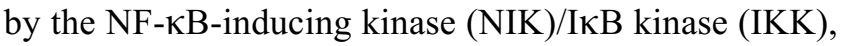
$\mathrm{NF}-\kappa \mathrm{B}$ gets free and translocates to the nucleus. Therefore, NIK and IKK are related to the activation of NF- $\kappa B$. In the present study, NFKBIA (usually called IKB -alpha) is substantially overexpressed. Meanwhile, FLJ14515, a gene involved in NIK-I- $\kappa \mathrm{B} / \mathrm{NF}-\kappa \mathrm{B}$ cascade is down-regulated in both chips. Besides, expression of $S A E 1$, a SUMO-1 related gene, is reduced in chip2. Site specific SUMO-1 attachement is necessary to the nuclear localization of NEMO - the regulatory subunit of the cytoplasmic IKK complex, and ultimately leads to the activation of IKK in the cytoplasm [19]. Overall, the down-regulation of genes relate to IKK and the up-regulation of IKB indicate that the activation of NF- $\kappa \mathrm{B}$ is inhibited at the very up-stream of the pathway during this process. In our previous studies, we found that exposure of $\mathrm{HeLa}$ cells to $\mathrm{As}_{2} \mathrm{O}_{3}$ /emodin caused a suppressed expression of NF- $\kappa \mathrm{B}$-driven genes [8], and this suppression might be linked to an attenuated DNA binding capacity of NF- $\kappa B$ (data unpublished). We also demonstrated that $\mathrm{NF}-\kappa \mathrm{B}$ activation plays an antiapoptotic role under resting state and in response to $\mathrm{As}_{2} \mathrm{O}_{3}$ exposure [7]. Taken together, we conclude that emodin exerts an inhibitory effect on anti-apoptotic NF$\mathrm{\kappa B}$ activation at multiple levels. Arsenic has been shown to have varying effects on NF- $\kappa \mathrm{B}$ activity, depending on the cell type and treatment intensity [9]. Activation of NF- $\kappa B$ stimulated by arsenic may confer resistance to arsenic cytotoxicity. Therefore the inhibition of NF- $\mathrm{KB}$ activation by emodin must contribute, at least partially, to its enhancement of arsenic cytotoxicity. Real time PCR shows that up-regulation of NFKBIA is largely abolished and downregulation of FLJ14515 is completely reversed by NAC. This shows that emodin affects NF- $\mathrm{BB}$ pathway in a ROSdependent fashion.

The ATM, PPMID and PIG8 genes that are involved in activation of p53 and induction of apoptosis by p53 are all up-regulated in chip1. The activation of ataxia-telangiectasia mutated (ATM) kinase is necessary to the induction and activation of $\mathrm{p} 53$ protein after ionizing radiation (IR) and certain other forms of oxidative stress [20]. Expression of Gpx is also increased. The induction of Gpx is an early event following p53 activation [21].

$H S F 1$ gene is up-regulated by emodin, and this up-regulation is again antagonized by NAC. Heat shock transcription factor 1 (HSF1) is responsible for the induction of heat shock protein in response to stress [22]. Several heat shock proteins are known to promote cell survival and prevent apoptosis during a wide variety of stress conditions including oxidative stress [23].

In addition to these genes known to be the signaling molecules involved in arsenic effects, emodin also induce the alternative signal pathways including PKC and AKT (all down-regulated) at different time points. Most of these molecules participate in the oxidative stress activate signal pathways, which implies that emodin influences arsenic effects on signaling via generation of ROS. The decrease of PKC delta, named PRKCD, and AKT1, is abolished by NAC, evidencing directly that the effects of emodin is ROSdependent. Crosstalk exists among these different signaling pathways and the final occurrence of apoptosis reflects the relative activity in survival/death balance.

\section{Emodin enhances arsenic effects on different organelle functions}

As compared to $\mathrm{As}_{2} \mathrm{O}_{3}$ alone-induced apoptosis, $\mathrm{As}_{2} \mathrm{O}_{3}$ / emodin cotreatment affected numerous genes encoding 
for organelle proteins, i.e. the proteins of mitochondrion, endoplasmic reticulum (ER), Golgi apparatus and lysosome. More dramatic gene expression changes linked to organelle structures and functions occurred at the early time point during emodin-enhanced apoptosis, among which many are known related to the initiation of cell death pathways.

Most of the genes encoding mitochondrial complex I and III are over-expressed in two chips. The genes encoding ATP synthase $/ \mathrm{H}^{+}$transporting mitochondrial $\mathrm{F} 0$ and F1 complex subunits are down-regulated in chip1, which indicated that the uncoupling of electron transport and oxidative phosphorylation occurred at the early time. VDAC-1 is part of a protein complex commonly referred to as the permeability transition (PT) pore [24]. Its decreased expression may be related to the changes of PT pore. The gene expression changes involved in PT pore may be related with what we reported that HeLa cells undergo a reduction in mitochondiral membrane potential $(\Delta \Psi \mathrm{m})$ with $\mathrm{As}_{2} \mathrm{O}_{3}$ /emodin cotreatment [8]. NAC prevents the down-regulation of $V D A C-1$.The thioredoxin reductase 1 (TXNRD1) gene is down-regulated in chip2, which indicates a perturbation in mitochondrial scavenging of ROS and mitochondrial apoptosis signaling [25].

Many genes encoding ER membrane, lumen and functional proteins are less expressed, such as genes Calumenin and COPA, which were involved in protein folding, sorting and transport between the ER and Golgi compartments $[26,27]$. Reticulocalbin and calnexin genes, both are $\mathrm{Ca}^{2+}$ binding ER luminal proteins, are respectively up and downregulated in chip1. The expression of inositol 1,4,5trisphosphate receptor (InsP3R) gene is blocked in chip2. InsP3R encodes a ligand-gated $\mathrm{Ca}^{2+}$-release channel and plays an important role in intracellular $\mathrm{Ca}^{2+}$ signaling in a wide variety of cell types [28]. The expression of TRAF2 and $e I F 2-\alpha$ genes is altered and they are reported to be the downstream effectors of Ire $1-\alpha$ and PERK, both involved in the ER unfolded protein response (UPR) [29, 30]. Thus, we suppose that two major mechanisms by which ER participates in the apoptosis, UPR and $\mathrm{Ca}^{2+}$ signaling [31], are influenced during the emodin-facilitated apoptosis.

The GD3 synthase ( $\alpha$-2,8-sialytransferase) and PI(3) $K$ genes that are known as apoptosis-signaling proteins located at Golgi membranes are respectively up-regulated in chip1 and chip2. GD3 could shuttle to mitochondria and induce mitochondrial membrane permeabilization (MMP) [32].

Lysosomal rupture is associated with the release of cathepsins and activation of PLA2 [33]. The phospholipase A2 gene (PLA2) is more expressed in chip1. Several lysosomal proteases including cathepsin $\mathrm{D}$ are down-regu- lated in two chips. In pro-oxidant-induced apoptosis, the release of cathepsin D and other lysosomal enzymes can promote mitochondrial oxidant production, cytochrome $\mathrm{c}$ release and apoptosis [34]. Thus it is possible that lysosome rupture has participated in the $\mathrm{As}_{2} \mathrm{O}_{3}$ /emodin-induced apoptosis.

\section{Emodin enhances arsenic effects on cell cycle blockage}

The expression of cyclinB2 gene is decreased. Cyclin $\mathrm{B} / \mathrm{Cdc} 2$ kinases activity has been identified as the principal component of mitosis promoting factor (MPF) [35], upon activity of which progression from $\mathrm{G} 2 \rightarrow \mathrm{M}$ phase is highly dependent [36]. The expression of both $C d k 4$ and retinoblastoma protein $1(p R b)$ are blocked while two cyclin Drelated genes are up-regulated. The $E 2 F$ gene expression is increased and several other downstream genes of $p R b$ including dihydrofolate reductase and $C d c 2$ are downregulated. At G1 checkpoint, the induction of D-type cyclins and subsequent phosphorylation of $\mathrm{pRb}$ determine whether or not the cell commits to the cell cycle and E2F family is related to this regulation $[37,38]$. While cyclin $\mathrm{B} /$ $\mathrm{Cdc} 2$ complex is essential for $\mathrm{G} 2$ checkpoint, the genes $A T M$ and PPMID that are related to DNA damage response/activation of $\mathrm{p} 53$ are found to be up-regulated. Cells with intact p53 function readily arrest in G1 after IR exposure and oxidative stress [39]. Thus, we can see that during $\mathrm{As}_{2} \mathrm{O}_{3}$ /emodin-induced apoptosis, both $\mathrm{G} 1$ and $\mathrm{G} 2$ checkpoints are affected, and several altered genes are common to cell cycle regulation and apoptosis.

Meanwhile, many genes related to proliferation, chromatin or chromosome organization and biogenesis and DNA repair are down-regulated in both chips, but mainly in chip2, indicating that these genes are influenced at the later time point.

\section{Emodin enhances arsenic effects on cytoskeleton changes}

We have found unexpectedly that the cotreatment of $\mathrm{As}_{2} \mathrm{O}_{3}$ /emodin induce surprisingly dramatic changes in cytoskeleton-related genes at both time points. These gene expression changes have probably participated in the three continuous cytoskeletal changing steps during apoptosisrelease, blebbing and condensation [40]. The expression of actin cross-linking-related gene macrophin 1 is blocked at the $6 \mathrm{~h}$ time point. Genes related to actin reorganization such as actin filament, actin organization and biogenesis are mostly down-regulated at the $24 \mathrm{~h}$ time point. The tubulin $\beta 4$, tubulin-specific chaperone $c$ and beta-tubulin folding protein genes as well as other genes involved in microtubule motor, microtubule based movement and microtubule process are down-regulated in both chips. Myosin-related gene expressions are altered in both chips. At 
the 6 and $24 \mathrm{~h}$ time points, actin $\alpha 1$ mRNA respectively decrease to $5 \%$ and $10 \%$, which may perturb the third step "condensation" (actin dissolution). NAC blocks and further reverses the down-regulation of actin $\alpha 1$ gene.

Among these proteins, some are known to be cleaved by caspases during apoptosis, such as actin, gas2, cadherin, keratin-19 and Tau [41]. One theory that attempt to explain the cell contraction, membrane blebbing and apoptotic body formation observed in apoptotic cells is that caspase-mediated proteolysis of cytoskeleton adhension proteins leads to a release from points of cell attachment followed by collapse of the cell [42].

The Rho GTPase signaling pathways related genes including RhoA in both chips, ROCK1 in chip2 and ROCK2 in chip1 are all down-regulated. The activation of RhoA, ROCK 1 and ROCK2 is essential for the cell contraction and membrane blebbing during apoptosis [41]. ARHA, one of the guanine nucleotide-exchange factors (GEFs) that catalyses GTP loading and activation of Rho proteins is also down- regulated. These results show that the $\mathrm{As}_{2} \mathrm{O}_{3} /$ emodin cotreatment induces a remarkable transcriptional change in the cytoskeleton components, some of which are up- or down-regulated early and violently, whereas the transcription of Rho GTPase and ROCKs are suppressed.

In addition to mediating the cytoskeleton change during apoptosis, Rho GTPases impinge on cell survival under a variety of circumstances. RhoA has been shown to induce phophorylation and activation of AKT and TGF $\beta$ to promote cell growth [43]. ROCK activity has been shown to be involved in tumor metastasis [44]. Therefore, we suppose that the attenuation of Rho GTPase signaling has probably contributed to the enhanced apoptotic susceptibility of HeLa cells to $\mathrm{As}_{2} \mathrm{O}_{3}$.

There are many other important genes, in addition to the genes cited above, affected by ROS. For instance, ATP binding cassette subfamily 1 is down-regulated, which may be related to the drug resistance; genes encoding iron channel are altered, which may play a role in cell apoptosis; genes encoding ubiquitin and proteasome are influenced, which may function in protein degradation.

Emodin enhances arsenic trioxide cytotoxicity in HeLa cells through intracellular ROS generation. This ROS generation may, as the present study evidenced, profoundly alter the gene expression, while simultaneously influence the activities of a series of pre-existed molecules, probably by a direct oxidative modification, as our previous data suggested. With alteration of intracellular redox state, emodin regulates multiple signaling pathways, affects organelle functions, blocks cell cycle progression, causes early cytoskeleton changes, and influences many other gene expression. The final outcome of a potentiated cell

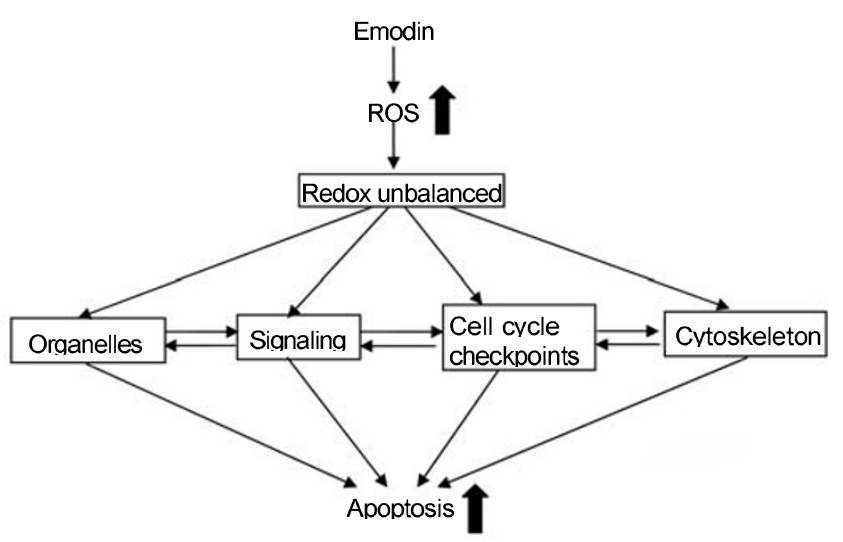

Fig. 7 A hypothetical model for how emodin facilitates $\mathrm{As}_{2} \mathrm{O}_{3}-$ induced apoptosis in HeLa cells through a series of regulatory events on gene expression. The boxes represent different groups of genes involved in this process. Emodin causes intracellular ROS generation and perturbs cellular redox. Gene expression is pronouncedly regulated by ROS, which play roles in signal transduction, organelle functions, cell cycle checkpoint, and cytoskeleton. The altered expression of these genes, together with their interplay, sensitizes HeLa cells to arsenic cytotoxicity.

death is likely to be the results of the interplay of all the aspects (Fig. 6). The gene expression profiles demonstrated here have provided us new clues for further study of molecular mechanism through which emodin enhances the sensitivity of tumor cells to $\mathrm{As}_{2} \mathrm{O}_{3}$ - and other anti-cancer drug-induced apoptosis.

\section{ACKNOWLEDGEMENTS}

This study was supported by grants from National Natural Science Foundation of China (No. 30170475) and Shanghai Municipal Education Commission (No. zdxk2001).

Received, Apr 30, 2005

Revised, May 20, 2005

Accepted, May 24, 2005

\section{REFERENCES}

1 Chen Z, Chen GQ, Shen ZX, Chen SJ, Wang ZY. Treatment of acute promyelocytic leukemia with arsenic compounds: in vitro and in vivo studies. Semin Hematol 2001; 38:26-36.

2 Jing Y, Dai J, Chalmers-Redman RM, Tatton WG, Waxman S. Arsenic trioxide selectively induces acute promyelocytic leukemia cell apoptosis via a hydrogen peroxide-dependent pathway. Blood 1999; 94:2102-11.

3 Zhou Y, Hileman EO, Plunkett W, Keating MJ, Huang P. Free radical stress in chronic lymphocytic leukemia cells and its role in cellular sensitivity to ROS-generating anticancer agents. Blood 2003; 101:4098-104. 
4 Gartenhaus RB, Prachand SN, Paniaqua M, Li Y, Gordon LI. Arsenic trioxide cytotoxicity in steroid and chemotherapy-resistant myeloma cell lines: enhancement of apoptosis by manipulation of cellular redox state. Clin Cancer Res 2002; 8:566-72.

5 Gao F, Yi J, Yuan JQ, Shi GY, Tang XM. The cell cycle related apoptotic susceptibility to arsenic trioxide is associated with the level of reactive oxygen species. Cell Res 2004; 14:81-5.

6 Yi J, Gao F, Shi G, et al. The inherent cellular level of reactive oxygen species: one of the mechanisms determining apoptotic susceptibility of leukemic cells to arsenic trioxide. Apoptosis. 2002; 7:209-15.

7 Yi J, Yang J, He R, et al. Emodin enhances arsenic trioxide-induced apoptosis via generation of reactive oxygen species and inhibition of survival signaling. Cancer Res 2004; 64:108-16.

8 Yang J, Li H, Chen YY, et al. Anthraquinones sensitize tumor cells to arsenic cytotoxicity in vitro and in vivo via reactive oxygen species-mediated dual regulation of apoptosis. Free Radical Biol Med 2004; 37:2027-41.

9 Bode AM, Dong Z. The paradox of arsenic: molecular mechanisms of cell trans formation and chemotherapeutic effects. Crit Rev Oncol Hematol 2002; 42:5-24.

10 Chen YC, Lin-Shiau SY, Lin JK. Involvement of reactive oxygen species and caspase 3 activation in arsenite-induced apoptosis. J Cell Physiol 1998; 177:324-33.

11 Gendron MC, Schrantz N, Metivier D, et al. Oxidation of pyridine nucleotides during Fas- and ceramide-induced apoptosis in Jurkat cells: correlation with changes in mitochondria, glutathione depletion, intracellular acidification and caspase 3 activation. Biochem J 2001; 353(Pt 2):357-67.

12 Cai X, Shen YL, Zhu Q, et al. Arsenic trioxide-induced apoptosis and differentiation are associated respectively with mitochondrial transmembrane potential collapse and retinoic acid signaling pathways in acute promyelocytic leukemia. Leukemia 2000; 14:262-70

13 Kitamura K, Minami Y, Yamamoto K, et al. Involvement of CD95-independent caspase 8 activation in arsenic trioxide-induced apoptosis. Leukemia 2000; 14:1743-50.

$14 \mathrm{Zhu}$ XH, Shen YL, Jing YK, et al. Apoptosis and growth inhibition in malignant lymphocytes after treatment with arsenic trioxide at clinically achievable concentrations. J Natl Cancer Inst 1999; 91:772-8.

15 Chou WC, Jie C, Kenedy AA. Role of NADPH oxidase in arsenic-induced reactive oxygen species formation and cytotoxicity in myeloid leukemia cells. Proc Natl Acad Sci U S A. 2004; 101:4578-83.

16 Kudoh M, Knee DA, Takayama S, Reed JC. Bag1 proteins regulate growth and survival of ZR-75-1 human breast cancer cells. Caner Res 2002; 62:1904-9.

17 Nicholson KM, Anderson NG. The protein kinase B/AKT signalling pathway in human malignancy. Cell Signal 2002; 14:38195.

18 Hutter D, Greene JJ. Influence of the cellular redox state on NFkappaB-regulated gene expression. J Cell Physiol 2000; 183:4552.

19 Huang TT, Wuerzberger-Davis SM, Wu ZH, Miyamoto S. Sequential modification of NEMO/IKKgamma by SUMO-1 and ubiquitin mediates NF-kappaB activation by genotoxic stress. Cell 2003; 115:565-76.

20 Banin S, Moyal L, Shieh S, et al. Enhanced phosphorylation of p53 by ATM in response to DNA damage. Science 1998; 281: 1674-7.

21 Tan M, Li S, Swaroop M, et al. Transcriptional activation of the human glutathione peroxidase promoter by $\mathrm{p} 53$. J Biol Chem 1999; 274:12061-6.

22 Pirkkala L, Nykanen P, Sistonen L. Roles of the heat shock transcription factors in regulation of the heat shock response and beyond. FASEB J 2001; 15:1118-31.

23 Jolly C, Morimoto RI. Role of the heat shock response and molecular chaperones in oncogenesis and cell death. J Natl Cancer Inst 2000; 92:1564-72.

24 Zamzami N, Kroemer G. The mitochondrion in apoptosis: how Pandora's box opens. Nat Rev Mol Cell Biol 2001; 2:67-71.

25 Tanaka T, Hosoi F, Yamaguchi-Iwai Y, et al. Thioredoxin-2 (TRX2 ) is an essential gene regulating mitochondria-dependent apoptosis. EMBO J, 2002; 21:1695-703.

26 Honore B, Vorum H. The CREC family, a novel family of multiple EF-hand, low-affinity $\mathrm{Ca}(2+)$-binding proteins localised to the secretory pathway of mammalian cells. FEBS Lett 2000; 466: $11-8$

27 Nickel W, Brugger B, Wieland FT. Protein and lipid sorting between the endoplasmic reticulum and the Golgi complex. Semin Cell Dev Biol 1998; 9:493-501.

28 Mikoshiba K. The InsP3 receptor and intracellular $\mathrm{Ca}^{+}$signaling. Curr Opin Neurobiol 1997; 7:339-45.

29 Katayama T, Imaizumi K, Sato N, et al. Presenilin-1 mutations downregulate the signalling pathway of the unfolded-protein response. Nat Cell Biol 1999; 1:479-85.

30 Patil, C, Walter P. Intracellular signaling from the endoplasmic reticulum to the nucleus: the unfolded protein response in yeast and mammals. Curr Opin Cell Biol 2001; 13:349-55.

31 Ferri KF, Kroemer G. Organelle-specific initiation of cell death pathways. Nat Cell Biol 2001; 3:E255-63.

32 Rippo MR, Malisan F, Ravagnan L, et al. GD3 ganglioside directly targets mitochondria in a bcl-2-controlled fashion. FASEB J 2000; 14:2047-54.

33 Breitbart H, Spungin B. The biochemistry of the acrosome reaction. Mol Hum Reprod 1997; 3:195-202.

34 Deiss LP, Galinka H, Berissi H, Cohen O, Kimchi A. Cathepsin $\mathrm{D}$ protease mediates programmed cell death induced by interferon-gamma, Fas/APO-1 and TNF-alpha. EMBO J 1996; 15: 3861-70.

35 Gautier J, Minshull J, Lohka M, et al. Cyclin is a component of maturation-promoting factor from Xenopus. Cell 1990; 60:48794.

36 Pines J, Hunter T. Human cyclins A and B1 are differentially located in the cell and undergo cell cycle-dependent nuclear transport. J Cell Biol 1991; 115:1-17.

37 Erikson E, Maller JL. Biochemical characterization of the p34cdc2 protein kinase component of purified maturation-promoting factor from Xenopus eggs. J Biol Chem 1989; 264:19577-82.

38 Sherr CJ. G1 phase progression: cycling on cue. Cell 1994; 79: 551-5.

39 Lukas J, Muller H, Bartkova J, et al. DNA tumor virus oncoproteins and retinoblastoma gene mutations share the ability to relieve the cell's requirement for cyclin D1 function in G1. J Cell Biol 1994; 125:625-38.

40 Mills JC, Stone NL, Pittman RN. Extranuclear apoptosis. The role of the cytoplasm in the execution phase. J Cell Biol 1999; 
146:703-8

41 Coleman ML, Olson MF. Rho GTPase signalling pathways in the morphological changes associated with apoptosis. Cell Death Differ 2002; 9:493-504.

42 Carragher NO, Fincham VJ, Riley D, Frame MC. Cleavage of focal adhesion kinase by different proteases during SRC-regulated transformation and apoptosis. Distinct roles for calpain and caspases. J Biol Chem 2001; 276: 4270-5.

43 Aznar S, Lacal JC. Rho signals to cell growth and apoptosis. Cancer Lett 2001; 165:1-10.

44 Takamura M, Sakamoto M, Genda T, et al. Inhibition of intrahepatic metastasis of human hepatocellular carcinoma by Rho-associated protein kinase inhibitor Y-27632. Hepatology 2001; 33: $577-81$ 